\title{
Facile Ultrasound-Assisted Synthesis of Copper Zinc Tin Sulfide Chalcogenide Nanoparticles for Thin Film Solar Cell Applications
}

\author{
Akanksha Paraye1, Manivannan Ramachandran', Noyel Victoria Selvam* \\ 1 Department of Chemical Engineering, National Institute of Technology Raipur, Raipur, 492010 Chhattisgarh, India \\ * Corresponding author, e-mail: snvictoria.che@nitrr.ac.in
}

Received: 31 August 2019, Accepted: 03 January 2020, Published online: 06 February 2020

\begin{abstract}
Single-step ultrasound-assisted synthesis of Copper Zinc Tin Sulfide nanoparticles (CZTS) has been studied at two different frequencies. While the effects of frequency on the particle size of the CZTS nanoparticles were insignificant, a noticeable change was observed in composition. As-obtained particles presented the amorphous nature and spherical morphology with a high degree of agglomeration. Annealing of the synthesized CZTS nanoparticles increased the crystallinity while the sulfur content decreased considerably. The polydispersity and agglomeration of the nanoparticles increased upon annealing. The as-obtained CZTS nanoparticles synthesized at $45 \mathrm{kHz}$ frequency presented a copper deprived and zinc-rich composition suitable for higher photo-conversion efficiency of the solar cells. The bandgap of the annealed and non-annealed particles ranged between $1.25 \mathrm{eV}$ and $1.65 \mathrm{eV}$.
\end{abstract}

Keywords

CZTS, sonochemical, frequency, annealing, solar cell

\section{Introduction}

With an increase in the worldwide population and scientific advancements, the demand for energy is constantly increasing. The conventional energy sources are insufficient to cater to this huge demand. The entire research community around the world is striving to find a promising alternative to address this energy crisis. Among the alternate energy sources, the most promising is solar energy and studies on developing different types of solar cells have gained momentum [1].

Silicon based solar cells offer good photoconversion efficiencies. However, they are expensive and require a thicker absorber layer because of the indirect optical band gap nature of the silicon [2]. This has led to the exploration of new solar cell materials, which can compete with the silicon-based solar cells. New absorber materials containing the elements copper (C), indium (I), gallium (G), selenium (Se) and sulfur (S) in different combinations such as CIGS, CIGSe, and CIS exhibit desirable characteristics for solar cell applications such as higher absorption coefficient and a direct optical bandgap closer to silicon [3]. However, the precursors such as indium and gallium are not available in abundance in nature.
Chalcogenide material copper zinc tin sulfide frequently termed as CZTS is another suitable material with abundant raw material supply. It is also preferred for its non-toxic nature [2]. Unlike silicon, CZTS has a direct band gap of $1.5 \mathrm{eV}$ and absorption coefficient greater than $10^{4} \mathrm{~cm}^{-1}$ which are highly desirable for photovoltaic applications. As a result, a thin layer of the CZTS absorber layer can work effectively when compared to a thick silicon layer resulting in light-weight modules [2, 4].

Different synthesis modes are possible for CZTS film or nanoparticles namely hybrid sputtering, pulsed laser deposition, and radio frequency magnetron sputtering which demand high temperature and pressure conditions making them sophisticated and energy-demanding [5]. Some of the simpler synthesis routes, such as liquid-phase reduction, Successive Ionic Layer Adsorption Reaction (SILAR), require more reaction time and involve multiple steps in the reaction [2]. Additionally, these techniques result in the production of poly-dispersed particles.

Ultrasound-assisted nanoparticle synthesis is advantageous because it involves less reaction time and gives products with uniform size $[6,7]$. These advantages are 
the result of acoustic streaming and acoustic cavitation, during which hot spots develop due to the collapsing bubble and a local temperature as high as $5000 \mathrm{~K}$ and local pressures above 1800 atm can be realized [8, 9]. In a typical system with water as the solvent, the intense pressure and temperature conditions promote the production of radicals like $\mathrm{H}$ and $\mathrm{OH}$ that further react to produce $\mathrm{H}_{2} \mathrm{O}_{2}$ and $\mathrm{H}$. The $\mathrm{H}_{2} \mathrm{O}_{2}$ and $\mathrm{H}$ are capable of accelerating the rate of chemical reactions by their strong oxidizing and reducing properties respectively $[9,10]$. This phenomenon has been applied for the nanoparticle synthesis of various metals and metal oxides [10].

Sonochemical synthesis of copper sulfide nanoparticles and CIGS nanoparticles has been reported extensively [11, 12]. One-step synthesis of CZTS nanoparticles using the sonochemical route is challenging and only scarce has been reported on the said topic $[6,13,14]$.

In a sonochemical synthesis method for CZTS by Liu et al. thioacetamide and 2-methoxyethanol were employed as sulfur source and solvent respectively [6]. The effect of sonication time on the characteristics of the synthesized CZTS nanoparticles was studied [6]. A two-step multi-bubble sonoluminescence method was reported for the synthesis of CZTS. This involved the synthesis of $\mathrm{Cu}_{2} \mathrm{SnS}_{3}$ in the first step followed by treatment with $\mathrm{ZnS}$ to yield CZTS [13]. Recently our group has reported a single-step route for the ultrasound-assisted synthesis of CZTS particles using glycine as the complexing agent in which the effect of $\mathrm{pH}$ was investigated [14].

The present work details a single-step ultrasound-assisted method for the synthesis of CZTS nanoparticles using citric acid as the complexing agent. The effects of the synthesis frequency and annealing on the particle properties have been studied in detail.

\section{Experimental}

Analytical grade precursors were used for the synthesis. The details of the precursors used for the synthesis and their composition are presented in Table 1. The precursor salts were added to the de-ionized water and mixed using

Table 1 Details of the precursor chemicals and their concentration

\begin{tabular}{lc}
\hline Chemicals & Concentration used (mM) \\
\hline Copper sulfate pentahydrate & 15 \\
Zinc sulfate heptahydrate & 30 \\
Tin (II) chloride & 8 \\
Sodium thiosulfate pentahydrate & 30 \\
Citric acid monohydrate & 20 \\
\hline
\end{tabular}

a magnetic stirrer for five min to obtain a greenish-yellow solution. The $\mathrm{pH}$ of this reaction mixture was adjusted to 3.5 with the help of potassium hydroxide solution.

Then the reaction mixture was transferred to a bath type ultrasonicator (Elmasonic xtra ST, Elma, Germany) [15]. The frequencies used for the synthesis were $45 \mathrm{kHz}$ and $25 \mathrm{kHz}$. Water was circulated into the bath to maintain the temperature at $40 \pm 1{ }^{\circ} \mathrm{C}$. The sonication was continued for an hour after which the nanoparticle dispersion formed was separated using a Remi 8C model centrifuge. The centrifuge was operated at $4000 \mathrm{rpm}$ and the process was carried out for $10 \mathrm{~min}$. The product thus collected after centrifugation was washed with de-ionized water under the same operating conditions. The aforementioned washing step was carried out three times to remove the impurities. The collected CZTS nanoparticles were dried in a hot air oven (B.P. Lab solutions, India) [16] at $85^{\circ} \mathrm{C}$ for $30 \mathrm{~min}$. To analyze the effect of annealing, the product was heated at $250{ }^{\circ} \mathrm{C}$ in a muffle furnace (Nanotec, Chennai, India) [17] for $20 \mathrm{~min}$ in an argon environment.

The crystallinity of the samples was investigated using X-ray diffraction (PANalytical $3 \mathrm{~kW}$ X'pert) [18] unit. Field emission gun-scanning electron microscopy (FEGSEM) (Model: JEOL-JSM 7600 F) [19] was used to analyze the morphology of the nanoparticles. The composition of the samples was studied using energy dispersive X-ray analysis (EDAX) (INCA 250 EDS) [19]. The FEG-SEM images were analyzed for the particle size distribution using ImageJ software. Care was taken to select a large number of representative samples during size analysis. Optical properties for the samples were studied using a UV-visible spectrophotometer (Model: Shimadzu, UV-1800) [20].

A potentiostat-galvanostat from $\mathrm{CH}$ instruments (CHI 6091E) [21] was used to carry out the electrochemical characterization studies. Before the electrochemical analysis, a coating of the CZTS nanoparticles was made on an Indium Tin Oxide coated (ITO) glass slide from Sigma Aldrich (Surface resistivity $8 \Omega \mathrm{sq}^{-1}$ ) using a spin coating unit (Model: SpinNXG- P2, Apex Instruments, India) [22]. Spin coating was done at $1000 \mathrm{rpm}$ speed with $20 \mathrm{kPa}$ pressure to hold the substrate. Three coating steps of five min duration were used. Since the sheet resistance $\left(R_{s}\right)$ varies with the particle nature and its thickness, care was taken to maintain the thickness at a constant value. The thickness of the coating was maintained at $5 \pm 0.2 \mu \mathrm{m}$. The $I-V$ characteristic studies were obtained for the CZTS layer sandwiched between two ITO glasses with and without a $200 \mathrm{~W}$ incandescent light source. 


\section{Results and discussion}

\subsection{Field emission gun scanning electron microscopy}

The morphology of the non-annealed and annealed CZTS samples synthesized at different frequencies was studied using FEG-SEM and the images of the same are shown in Fig. 1. The size distribution of the samples is shown in the inset in Fig. 1. The compositional analysis for the same is presented in Table 2. It is observed from Fig. 1, that both non-annealed and annealed CZTS particles synthesized at frequencies $25 \mathrm{kHz}$ and $45 \mathrm{kHz}$ present a spherical shape. Most of the studies report the formation of spherical nanoparticles in the presence of ultrasound irradiation [8]. Size analysis of the non-annealed samples from both frequencies shows particles between $5 \mathrm{~nm}$ and $30 \mathrm{~nm}$ with the majority of the particles around $15 \mathrm{~nm}$ to $20 \mathrm{~nm}$. In acoustic cavitation, the mechanical energy effects due to the collapsing bubble are dependent on the bubble size which in turn varies with the frequency.

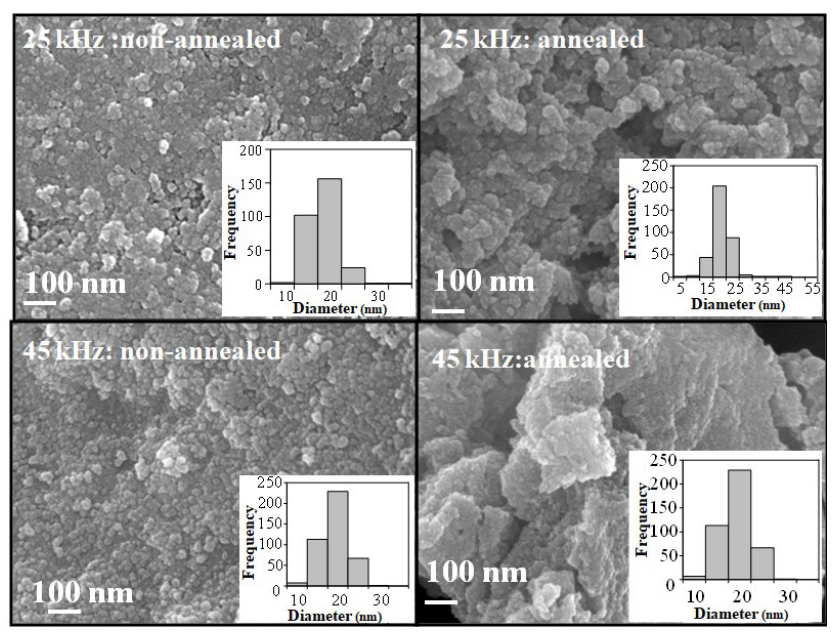

Fig. 1 FEG-SEM images of the CZTS samples synthesized at different conditions. Magnification of the images $100,000 \times$

Table 2 Elemental composition of the CZTS nanoparticles synthesized at different frequencies. (NA-Non-annealed, A-annealed)

\begin{tabular}{lcccc}
\hline & \multicolumn{5}{c}{ Atomic \% } \\
Elements & $25 \mathrm{kHz}$ & $45 \mathrm{kHz}$ & $25 \mathrm{kHz}$ & $45 \mathrm{kHz}$ \\
& $(\mathrm{NA})$ & $(\mathrm{NA})$ & $(\mathrm{A})$ & $(\mathrm{A})$ \\
\hline $\mathrm{Cu}$ & 26.7 & 22.0 & 35.4 & 17.2 \\
$\mathrm{Zn}$ & 9.2 & 13.7 & 7.0 & 12.8 \\
$\mathrm{Sn}$ & 7.5 & 10.4 & 17.0 & 24.8 \\
$\mathrm{~S}$ & 50.5 & 54.0 & 40.6 & 45.2 \\
{$[\mathrm{~S}] /[\mathrm{Cu}]$} & 1.3 & 1.9 & 1.1 & 2.6 \\
{$[\mathrm{Zn}] /[\mathrm{Sn}]$} & 1.2 & 1.3 & 0.4 & 0.5 \\
{$[\mathrm{Cu}] /[\mathrm{Zn}+\mathrm{Sn}]$} & 1.6 & 0.9 & 1.5 & 0.5 \\
{$[\mathrm{~S}] /[\mathrm{Cu}+\mathrm{Sn}+\mathrm{Zn}]$} & 1.2 & 1.2 & 0.7 & 0.8 \\
\hline
\end{tabular}

With an increase in frequency, the bubble size decreases and the mechanical effects become less [10]. In the present case, if the mechanical effects have played a significant role, then the use of $45 \mathrm{kHz}$ frequency would have resulted in larger sized particles. However, no significant variation in size is noticed. Hence the mechanical effects of acoustic cavitation did not influence the particle size significantly. The non-annealed particles synthesized at $25 \mathrm{kHz}$ exhibit a compact and denser aggregate pattern. The particles produced at $45 \mathrm{kHz}$ comprise of comparatively less dense aggregates. The aggregate formation is preferred for photovoltaic applications because it poses resistance to the removal of the charge carrying units: electron and holes generated by the incident solar radiation [23, 24].

The non-annealed CZTS nanoparticles in both the cases present decreased poly-dispersity. On the other hand, annealed nanoparticles from both frequencies show increased poly-dispersity and agglomeration. Due to the increased surface energy during annealing, particles fuse resulting in increased aggregate formation. This fusion process of the particles also causes the growth of a few grains which increases poly-dispersity [25-27]. Size analysis of the annealed particles shows the size range between $10 \mathrm{~nm}$ and $45 \mathrm{~nm}$. From Table 2, it is obvious that the non-annealed CZTS particles synthesized at $45 \mathrm{kHz}$ frequency show $[\mathrm{S}] /[\mathrm{Cu}],[\mathrm{Cu}] /([\mathrm{Zn}]+[\mathrm{Sn}])$ and $[\mathrm{S}] /([\mathrm{Cu}]+[\mathrm{Zn}]+[\mathrm{Sn}])$ ratios $1.9,0.9$ and 1.2 which are closer to the required value of 2, 1 and 1 respectively [24, 28]. The ratio of $\mathrm{Zn}$ to $\mathrm{Sn}$ is also closer to the required value of 1 . The sample synthesized at $45 \mathrm{kHz}$ thus show copper poor and $\mathrm{Zn}$ rich behavior which is preferred for excellent photovoltaic performance when compared to the stoichiometric CZTS $[24,28,29]$. Studies have shown that kesterite CZTS with a $[\mathrm{Cu}] /([\mathrm{Zn}]+[\mathrm{Sn}])$ value approximately equal to 0.9 and $[\mathrm{Zn}] /[\mathrm{Sn}]$ approximately equal to 1.25 was found to offer better performance of the solar cell devices [28]. Similarly, both samples present a significant drop in the sulfur composition upon annealing. The annealing process leads to the escape of volatile $\mathrm{S}$, and hence a drop in the sulfur composition is observed in the annealed samples [30].

\subsection{X-ray diffraction}

The X-ray diffraction results for the CZTS samples synthesized at frequencies $25 \mathrm{kHz}$ and $45 \mathrm{kHz}$ are shown in Fig. 2 and Fig. 3 respectively.

The non-annealed CZTS samples synthesized at both frequencies show amorphous nature. The intensity of the peaks is very small. The formation of amorphous 


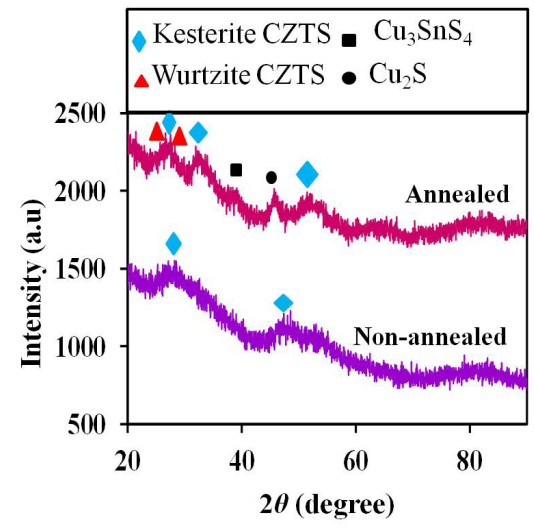

Fig. 2 X-ray diffraction spectra of the samples synthesized at $25 \mathrm{kHz}$

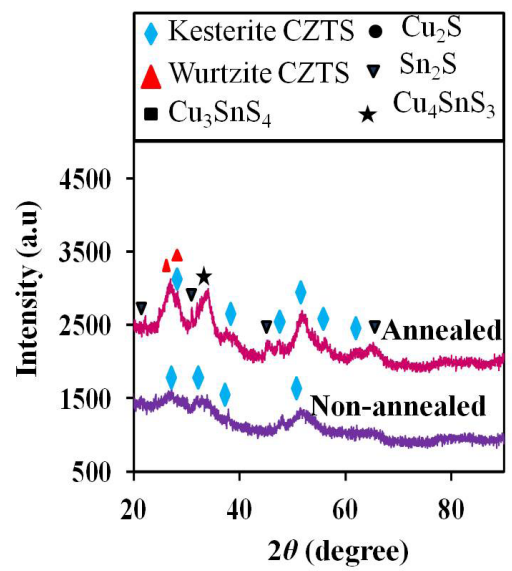

Fig. 3 X-ray diffraction spectra of the samples synthesized at $45 \mathrm{kHz}$

particles in ultrasound synthesis is due to the higher cooling rates observed in the hot spots [8]. The non-annealed sample synthesized at $25 \mathrm{kHz}$ shows the presence of peaks at $28.50^{\circ}, 32.79^{\circ}$ and $47.30^{\circ}$ which refers to the [112], [020] and [220] planes of kesterite phase CZTS [COD 96-9004751]. Annealing improves the crystallinity which can be confirmed by the increase in the peak intensities [27]. The annealed CZTS samples in both cases show the existence of secondary phases. Presence of volatile elements causes the breakdown of CZTS which results in the formation of secondary phases which sometimes may be lost due to volatile nature. Some secondary phases formed will further react to form some other compounds [31, 32]. The non-annealed samples synthesized at $45 \mathrm{kHz}$ shows the presence of wurtzite and kesterite forms of CZTS [33-35].

\subsection{Optical characteristics}

Fig. 4 shows the optical absorbance pattern of the annealed and non-annealed CZTS samples synthesized at both frequencies.

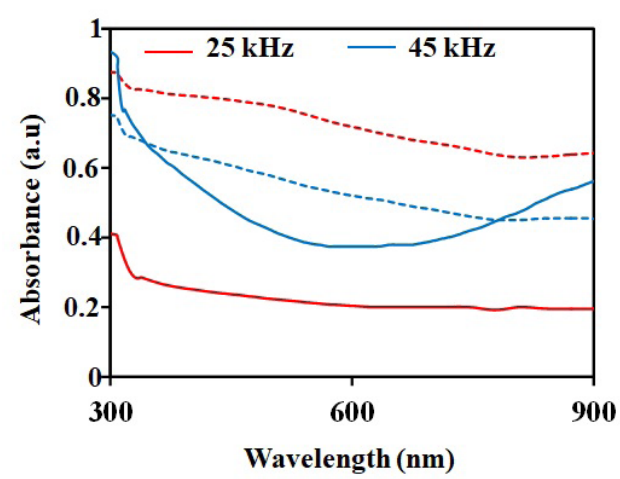

Fig. 4 UV-vis absorbance spectra for the annealed and non-annealed samples synthesized at different frequencies. Solid lines represent nonannealed samples and dotted lines represent annealed samples.

The absorbance spectra match well with the earlier reports on CZTS optical characterization using UV-vis spectroscopy $[23,24,36]$. The absorbance spectra show that the non-annealed and annealed CZTS samples synthesized at both frequencies show significant absorbance in the entire visible spectrum and the infra-red range. Similar behavior has been reported for the CZTS nanoparticles synthesized using hydrothermal route [23]. The annealing process increases the absorbance for both samples. The absorption edge shifts to a higher wavelength with annealing for both samples [37]. Tauc's equation relates the optical band gap $\left(E_{g}\right)$ with the absorption coefficient $(\alpha)$ as shown in Eq. (1) [38],

$\alpha=\left[A\left(E-E_{g}\right)^{n}\right] / E$.

In the Tauc's relation presented above (Eq. (1)) the photon energy $(E)$ is in $\mathrm{eV}$, and the constant $n$ is 0.5 for direct allowed, 1.5 for indirect forbidden and 3 for indirect allowed materials respectively [38]. The Tauc plots for the annealed and non- annealed samples are shown in Fig. 5. The band gap is estimated from the Tauc plot by extrapolation of the straight line region to the $\mathrm{x}$-axis where the absorption coefficient is zero.

The bandgap values were calculated as $1.62 \mathrm{eV}$ and $1.6 \mathrm{eV}$ for the non-annealed CZTS samples synthesized at $45 \mathrm{kHz}$ and $25 \mathrm{kHz}$ respectively. The bandgap decreases for the annealed samples and they are $1.35 \mathrm{eV}$ and $1.25 \mathrm{eV}$ for the samples synthesized at $25 \mathrm{kHz}$ and $45 \mathrm{kHz}$ respectively. Though the standard bandgap value for the CZTS is $1.5 \mathrm{eV}$ the reported bandgap values from literature range between $1.4 \mathrm{eV}$ and $1.7 \mathrm{eV}$ [30]. The witnessed changes in the bandgap values are due to the change in the composition that arises out of secondary phases [30]. 

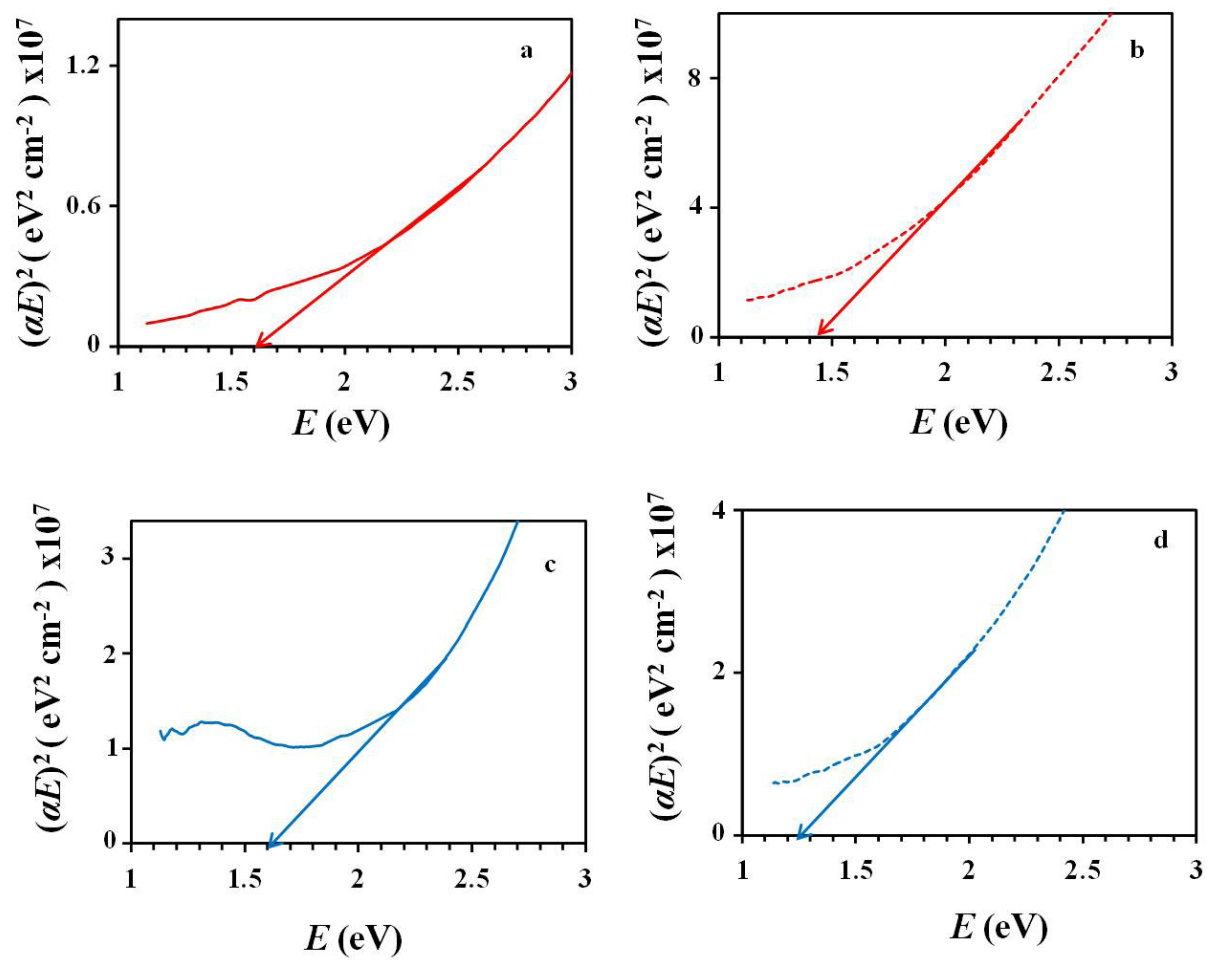

Fig. 5 Tauc plot for the annealed and non-annealed samples synthesized using different frequencies

(a) $25 \mathrm{kHz}-n o n$ annealed (b) $25 \mathrm{kHz}$ - annealed (c) $45 \mathrm{kHz}-n o n$ annealed (d) $45 \mathrm{kHz}$ - annealed

\subsection{Current-voltage (I-V) characteristics}

The $I-V$ characteristics curves for the ITO-CZTS sandwich with and without light source are shown in Fig. 6 and Fig. 7. The $I-V$ plots present a straight line pattern indicating Ohmic behavior.

Similar Ohmic behavior for $I-V$ characterization has been reported for CZTS thin films by other research groups [39-43]. The sheet resistance $\left(R_{s}\right)$ for the CZTS film coating can be calculated from the slope $(S)$ of the $I-V$ curves using Eq. (2) [43].

$R_{s}=4.53(S)$

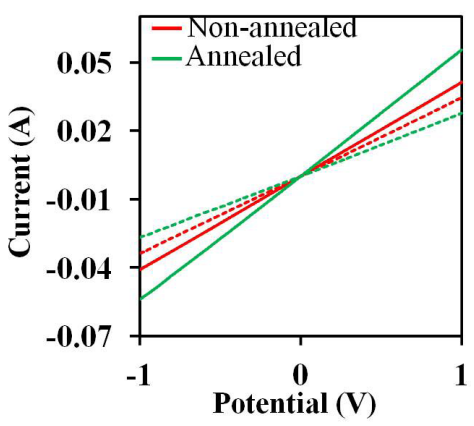

Fig. $6 I-V$ characterization plots for ITO/CZTS/ITO sandwich formed using CZTS nanoparticles synthesized at $25 \mathrm{kHz}$. Solid lines represent behavior in the presence of light and dotted lines represent the trend in dark.
The $R_{s}$ values calculated for the CZTS thin films are listed in Table 3. The decrease in $R_{s}$ values upon exposure to the light source shows that the material is suitable for solar cell applications. The $R_{s}$ values $(82 \Omega-169 \Omega)$ match well with the results of similar studies on CZTS film [43].

\section{Conclusions}

One-step sonochemical route was successfully applied for the synthesis of copper zinc tin sulfide (CZTS) nanoparticles. The characteristics of the particles obtained using different ultrasound frequencies varied appreciably. The particle morphology and the size did not alter

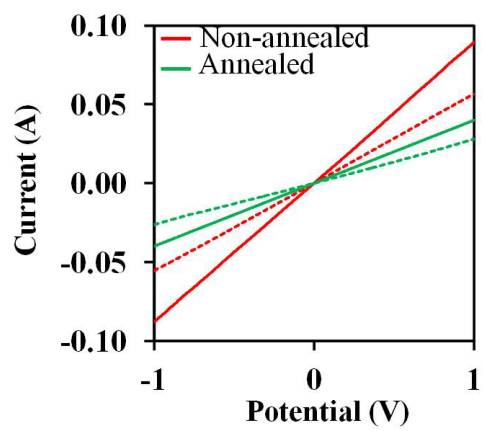

Fig. $7 I-V$ characterization plots for ITO/CZTS/ITO sandwich formed using CZTS nanoparticles synthesized at $45 \mathrm{kHz}$. Solid lines represent behavior in the presence of light and dotted lines represent the trend in dark. 
Table $3 R_{s}$ values from the IV characterization of the CZTS films formed on ITO glass slide

\begin{tabular}{|c|c|c|c|}
\hline \multicolumn{4}{|c|}{$R_{s}(\Omega)$} \\
\hline \multicolumn{2}{|c|}{$25 \mathrm{kHz}$} & \multicolumn{2}{|c|}{$45 \mathrm{kHz}$} \\
\hline Light & Dark & Light & Dark \\
\hline \multicolumn{4}{|c|}{ Non-annealed } \\
\hline 109 & 132.2 & 50.7 & 80.2 \\
\hline \multicolumn{4}{|c|}{ Annealed } \\
\hline 82 & 168 & 113.2 & 169.4 \\
\hline
\end{tabular}

significantly with the applied ultrasound frequency. The frequency of the ultrasound does change the chemical composition of the CZTS nanoparticles synthesized. The as-synthesized and annealed CZTS nanoparticles formed dense aggregates which is preferred for solar cell applications. Moreover, composition analysis of

\section{References}

[1] Manivannan, R., Victoria, S. N. "Preparation of chalcogenide thin films using electrodeposition method for solar cell applications A review", Solar Energy, 173, pp. 1144-1157, 2018. https://doi.org/10.1016/j.solener.2018.08.057

[2] Shiyani, T., Raval, D., Patel, M., Mukhopadhyay, I., Ray, A. "Effect of initial bath condition and post-annealing on co-electrodeposition of $\mathrm{Cu}_{2} \mathrm{ZnSnS}_{4}$ ", Materials Chemistry and Physics, 171, pp. 63-72, 2016.

https://doi.org/10.1016/j.matchemphys.2015.11.001

[3] Scragg, J. J., Dale, P. J., Peter, L. M. "Towards sustainable materials for solar energy conversion: Preparation and photoelectrochemical characterization of $\mathrm{Cu}_{2} \mathrm{ZnSnS}_{4}$ ", Electrochemistry Communications, 10(4), pp. 639-642, 2008. https://doi.org/10.1016/j.elecom.2008.02.008

[4] Sarswat, P. K., Snure, M., Free, M. L., Tiwari, A. "CZTS thin films on transparent conducting electrodes by electrochemical technique", Thin Solid Films, 520(6), pp. 1694-1697, 2012. https://doi.org/10.1016/j.tsf.2011.07.052

[5] Pawar, B. S., Pawar, S. M., Shin, S. W., Choi, D. S., Park, C. J., Kolekar, S. S., Kim, J. H. "Effect of complexing agent on the properties of electrochemically deposited $\mathrm{Cu}_{2} \mathrm{ZnSnS}_{4}$ (CZTS) thin films", Applied Surface Science, 257(5), pp. 1786-1791, 2010. https://doi.org/10.1016/j.apsusc.2010.09.016

[6] Liu, Y., Xu, J., Ni, Z., Fang, G., Tao, W. "One-step sonochemical synthesis route towards kesterite $\mathrm{Cu}_{2} \mathrm{ZnSnS}_{4}$ nanoparticles", Journal of Alloys and Compounds, 630, pp. 23-28, 2015. https://doi.org/10.1016/j.jallcom.2015.01.033

[7] Jiang, L.-P., Xu, S., Zhu, J.-M., Zhang, J.-R., Zhu, J.-J., Chen, H.-Y. "Ultrasonic-Assisted Synthesis of Monodisperse Single-Crystalline Silver Nanoplates and Gold Nanorings", Inorganic Chemistry, 43(19), pp. 5877-5883, 2004. https://doi.org/10.1021/ic049529d the non-annealed CZTS nanoparticles synthesized using $45 \mathrm{kHz}$ frequency showed a copper-poor and zinc-rich composition which is preferred due to enhanced performance characteristics. Annealing of the samples resulted in the escape of volatile $\mathrm{S}$ compounds. Annealing process resulted in a red-shift of the band gap due to the altered stoichiometry. The as-synthesized particles from $45 \mathrm{kHz}$ ultrasound frequency showed characteristics suitable for solar cell material.

\section{Acknowledgement}

Authors would like to thank the Department of Science and Technology - SERB, India for financing the research work under the Grant No. SR/FTP/ETA-412/2013 and Department of Science and Technology-Solar Energy Research Initiative (DST-SERI), India for the analytical facilities.

[8] Bang, J. H., Suslick, K. S. "Applications of Ultrasound to the Synthesis of Nanostructured Materials", Advanced Materials, 22(10), pp. 1039-1059, 2010. https://doi.org/10.1002/adma.200904093

[9] Ashokkumar, M. "The characterization of acoustic cavitation bubbles - An overview", Ultrasonics Sonochemistry, 18(4), pp. 864-872, 2011. https://doi.org/10.1016/j.ultsonch.2010.11.016

[10] Okitsu, K., Yue, A., Tanabe, S., Matsumoto, H., Yobiko, Y., Yoo, Y. "Sonolytic Control of Rate of Gold( III) Reduction and Size of Formed Gold Nanoparticles: Relation between Reduction Rates and Sizes of Formed Nanoparticles", Bulletin of the Chemical Society of Japan, 75(10), pp. 2289-2296, 2002. https://doi.org/10.1246/bcsj.75.2289

[11] Badgujar, A. C., Dusane, R. O., Dhage, S. R. "Sonochemical synthesis of $\mathrm{CuIn}_{0.7} \mathrm{Ga}_{0.2} \mathrm{Se}_{2}$ nanoparticles for thin film photo absorber application", Materials Science in Semiconductor Processing, 81, pp. 17-21, 2018 https://doi.org/10.1016/j.mssp.2018.03.001

[12] Jesionek, M., Nowak, M., Szperlich, P., Kępińska, M., Mistewicz, K., Toroń, B., Stróż, D., Szala, J., Rzychoń, T. "Properties of Sonochemically Prepared $\mathrm{CuIn}_{x} \mathrm{Ga}_{1-x} \mathrm{~S}_{2}$ and $\mathrm{CuIn}_{x} \mathrm{Ga}_{1-x} \mathrm{Se}_{2}$ ", Acta Physica Polonica A, 126(5), pp. 1107-1109, 2014. https://doi.org/10.12693/APhysPolA.126.1107

[13] Park, J., Song, M., Jung, W. M., Lee, W. Y., Kim, H., Kim, Y., Hwang, C., Shim, I.-W. "Synthesis of $\mathrm{Cu}_{2} \mathrm{SnS}_{3}$ and $\mathrm{Cu}_{2} \mathrm{ZnSnS}_{4}$ nanoparticles with tunable $\mathrm{Zn} / \mathrm{Sn}$ ratios under multibubble sonoluminescence conditions", Dalton Transactions, 42(29), pp. 10545-10550, 2013. https://doi.org/10.1039/C3DT50849H 
[14] Manivannan, R., Sahu, D., Selvaraju, N., Victoria, S. N. "Single Step Sonochemical Synthesis of copper zinc tin sulfide nanoparticles", Journal of Scientific and Industrial Research (JSIR), 78(2), pp. 102-105, 2019. [online] Available at: http://nopr.niscair.res.in/handle/123456789/45763 [Accessed: 14 November 2019]

[15] Elma "Elmasonic xtra ST", [online] Available at: https://www. elma-ultrasonic.com/fileadmin/downloads/Produktprofile/ Produktprofile_EN/Ultraschallgeraete/Elmasonic_xtra_ST/PP Elmasonic_xtra_ST_EN.pdf [Accessed: 16 December 2019]

[16] BP Lab India "Hot Air Oven", [online] Available at: http://www. bplabindia.com/hot-air-oven.htm [Accessed: 16 December 2019]

[17] Nanotec "Oxidation furnace", [online] Available at: http://nanoteclab.com/oxidation-furnace/ [Accessed: 16 December 2019]

[18] Malvern "X-ray diffraction", [online] Available at: https://www. malvernpanalytical.com/en/products/technology/x-ray-diffraction [Accessed: 16 December 2019]

[19] Jeol "JSM-7600F Schottky Field Emission Scanning Electron Micrsocope", [online] Available at: https://www.jeol.co.jp/en/ products/detail/JSM-7600F.html [Accessed: 16 December 2019]

[20] Shimadzu "UV-1280", [online] Available at: https://www.shimadzu.com/an/molecular_spectro/uv/uv-1280.html [Accessed: 16 December 2019]

[21] $\mathrm{CH}$ instruments "600E Potentiostat/Galvanostat", [online] Available at: https://www.chinstruments.com/chi600.shtml [Accessed: 16 December 2019]

[22] Apex instruments "Spin Coating Unit", [online] Available at: http://www.apexicindia.com/products/spin-coating-unit [Accessed: 16 December 2019]

[23] Camara, S. M., Wang, L., Zhang, X. "Easy hydrothermal preparation of $\mathrm{Cu}_{2} \mathrm{ZnSnS}_{4}$ (CZTS) nanoparticles for solar cell application", Nanotechnology, 24(49), Article number: 495401, 2013. https://doi.org/10.1088/0957-4484/24/49/495401

[24] Aldalbahi, A., Mkawi, E. M, Ibrahim, K., Farrukh, M. A. "Effect of sulfurization time on the properties of copper zinc tin sulfide thin films grown by electrochemical deposition", Scientific Reports, 6 , Article number: 32431, 2016. https://doi.org/10.1038/srep32431

[25] Du, S., Li, Y. "Effect of Annealing on Microstructure and Mechanical Properties of Magnetron Sputtered Cu Thin Films", 2015, Article ID: 969580, 2015.

https://doi.org/10.1155/2015/969580

[26] Engberg, S., Canulescu, S., Schou, J. "Liquid phase assisted grain growth in $\mathrm{Cu}_{2} \mathrm{ZnSnS}_{4}$ nanoparticle thin films by alkali element incorporation", 8(13), pp. 7152-7158, 2018. https://oi.org/10.1039/C7RA13472J

[27] Mallika, A. N., Reddy, A. R., Reddy, K. V. "Annealing effects on the structural and optical properties of $\mathrm{ZnO}$ nanoparticles with PVA and CA as chelating agents", 4(2), pp. 123-129, 2015. https://doi.org/10.1007/s40145-015-0142-4

[28] Mitzi, D. B., Gunawan, O., Todorov, T. K., Wang, K., Guha, S. "The path towards a high-performance solution-processed kesterite solar cell", Solar Energy Materials and Solar Cells, 95(6), pp. 1421-1436, 2011.

https://doi.org/10.1016/j.solmat.2010.11.028
[29] Chen, J., Wang, F., Yang, B., Peng, X., Chen, Q., Zou, J., Dou, X. "Fabrication of $\mathrm{Cu}_{2} \mathrm{ZnSnS}_{4}$ Thin Films Based on Facile Nanocrystals-Printing Approach with Rapid Thermal Annealing (RTA) Process", Coatings, 9(2), Article number: 130, 2019. https://doi.org/10.3390/coatings9020130

[30] Malerba, C., Biccari, F., Ricardo, C. L. A., Valentini, M., Chierchia, R., Müller, M., Santoni, A., Emilia, E., Mangiapane, P., Scardi, P., Mittiga, A. "CZTS stoichiometry effects on the band gap energy", Journal of Alloys and Compounds, 582, pp. 528-534, 2014.

https://doi.org/10.1016/j.jallcom.2013.07.199

[31] Whittles, T. J. "Electronic Characterisation of Earth-Abundant Sulphides for Solar Photovoltaics", PhD Thesis, University of Liverpool, 2018.

https://doi.org/10.1007/978-3-319-91665-1

[32] Paire, M., Delbos, S., Vidal, J., Naghavi, N., Guillemoles, J. F. "Chalcogenide Thin-Film Solar Cells", In: Conibeer, G., Willoughby, A. (eds.) Solar Cell Materials: Developing Technologies, John Wiley \& Sons, West Sussex, UK, 2014, pp. 145-215.

https://doi.org/10.1002/9781118695784.ch7

[33] Li, Z., Lui, A. L. K., Lam, K. H., Xi, L., Lam, Y. M. "PhaseSelective Synthesis of $\mathrm{Cu}_{2} \mathrm{ZnSnS}_{4}$ Nanocrystals using Different Sulfur Precursors", Inorganic Chemistry, 53(20), pp. 10874-10880, 2014. https://doi.org/10.1021/ic500956n

[34] Lu, X., Zhuang, Z., Peng, Q., Li, Y. "Wurtzite $\mathrm{Cu}_{2} \mathrm{ZnSnS}_{4}$ nanocrystals: A novel quaternary semiconductor", Chemical Communications, 47(11), pp. 3141-3143, 2011. https://doi.org/10.1039/c0cc05064d

[35] Li, M., Zhou, W.-H., Guo, J., Zhou, Y.-L., Hou, Z.-L., Jiao, J., Zhou, Z.-J., Du, Z.-L., Wu, S.-X. "Synthesis of Pure Metastable Wurtzite CZTS Nanocrystals by Facile One-Pot Method", Journal of Physical Chemistry C, 116(50), pp. 26507-26516, 2012. https://doi.org/10.1021/jp307346k

[36] Saha, S. K., Guchhait, A., Pal, A. J. "Cu $\mathrm{ZnSnS}_{4}$ (CZTS) nanoparticle based nontoxic and earth-abundant hybrid pn-junction solar cells", Physical Chemistry Chemical Physics, 14(22), pp. 8090-8096, 2012. https://oi.org/10.1039/c2cp41062a

[37] Chernomordik, B. D., Béland, A. E., Trejo, N. D., Gunawan, A. A., Deng, D. D., Mkhoyan, K. A., Aydil, E. S. "Rapid facile synthesis of $\mathrm{Cu}_{2} \mathrm{ZnSnS}_{4}$ nanocrystals", Journal of Materials Chemistry A, 2(27), pp. 10389-10395, 2014. https://doi.org/10.1039/C4TA01658K

[38] Paraye, A., Sani, R., Ramachandran, M., Selvam, N. V. "Effect of $\mathrm{pH}$ and sulfur precursor concentration on electrochemically deposited CZTS thin films using glycine as the complexing agent", Applied Surface Science, 435, pp. 1249-1256, 2018. https://doi.org/10.1016/j.apsusc.2017.11.210

[39] Ansari, M. Z., Khare, N. "Structural and optical properties of CZTS thin films deposited by ultrasonically assisted chemical vapour deposition", Journal of Physics D: Applied Physics, 47(18), Article number: 185101, 2014. https://doi.org/10.1088/0022-3727/47/18/185101 
[40] Kannan, A. G., Manjulavalli, T. E., Chandrasekaran, J. "Influence of Solvent on the Properties of CZTS Nanoparticles", Procedia Engineering, 141, pp. 15-22, 2016.

https://doi.org/10.1016/j.proeng.2015.08.1112

[41] Ghediya, P. R., Chaudhuri, T. K. "Dark and photo-conductivity of doctor-bladed CZTS films above room temperature", Journal of Physics D: Applied Physics, 48(45), Article number: 455109, 2015. https://oi.org/10.1088/0022-3727/48/45/455109
[42] Jiang, H., Dai, P., Feng, Z., Fan, W., Zhan, J. "Phase selective synthesis of metastable orthorhombic $\mathrm{Cu}_{2} \mathrm{ZnSnS}_{4}$ ", Journal of Materials Chemistry, 22(15), pp. 7502-7506, 2012.

https://doi.org/10.1039/C2JM16870G

[43] Henry, J., Mohanraj, K., Sivakumar, G. "Electrical and optical properties of CZTS thin films prepared by SILAR method", Journal of Asian Ceramic Societies, 4(1), pp. 81-84, 2016. https://oi.org/10.1016/j.jascer.2015.12.003 